Revista Legado de Arquitectura y Diseño ISSN: 2007-3615

ISSN: 2448-749X

legado_fad@yahoo.com.mx

Universidad Autónoma del Estado de México México

\title{
LA PARTICIPACIÓN DEL DISEÑO GRÁFICO EN LA SALVAGUARDIA DEL PATRIMONIO CULTURAL INMATERIAL. CASO: EL SEÑOR DEL CERRITO EN JIQUIPILCO, ESTADO DE MÉXICO
}

Mora-Torres, Magali; Villar-García, María Gabriela; Maldonado-Reyes, Ana Aurora

LA PARTICIPACIÓN DEL DISEÑO GRÁFICO EN LA SALVAGUARDIA DEL PATRIMONIO CULTURAL

INMATERIAL. CASO: EL SEÑOR DEL CERRITO EN JIQUIPILCO, ESTADO DE MÉXICO

Revista Legado de Arquitectura y Diseño, vol. 2019, núm. 26, 2019

Universidad Autónoma del Estado de México, México

Disponible en: http://www.redalyc.org/articulo.oa?id=477961406002

Esta obra está bajo una Licencia Creative Commons Atribución-NoComercial-SinDerivar 4.0 Internacional. 
Revista Legado de Arquitectura y Diseño, vol. 2019, núm. 26, 2019

Universidad Autónoma del Estado de México, México

Recepción: 18 Junio 2018 Aprobación: 04 Febrero 2019

Redalyc: http://www.redalyc.org/ articulo.oa?id $=477961406002$

\section{BY-NC-ND}

\section{LA PARTICIPACIÓN DEL DISEÑO GRÁFICO EN LA SALVAGUARDIA DEL PATRIMONIO CULTURAL INMATERIAL. CASO: EL SEÑOR DEL CERRITO EN JIQUIPILCO, ESTADO DE MÉXICO}

\author{
THE PARTICIPATION OF GRAPHIC DESING \\ IN THE INTANGIBLE CULTURAL HERITAGE \\ SAFEGUARDING. CASE OF STUDY: EL SEÑOR DEL \\ CERRITO EN JIQUIPILCO, ESTADO DE MÉXICO \\ Magali Mora-Torres maghalymora@gmail.com \\ Universidad Autónoma del Estado de México, México \\ María Gabriela Villar-García \\ investigacion.fad.villar@gmail.com \\ Universidad Autónoma del Estado de México, México \\ Ana Aurora Maldonado-Reyes eurekaana@gmail.com \\ Universidad Autónoma del Estado de México, México
}

Resumen: El presente artículo tiene como objetivo exponer las posibilidades de la participación del diseño gráfico como disciplina social en la generación de inventarios del patrimonio cultural inmaterial, a través de la imagen, en lo particular, de la manifestación cultural del Señor del Cerrito en Jiquipilco, Estado de México. Se expone un conjunto de metodologías que permiten el análisis de la imagen desde la teoría de los imaginarios colectivos como una apuesta desde el diseño gráfico para salvaguarda del PCI fundamentada en la propuesta que realiza la UNESCO para este tipo de prácticas , así como desde la teoría de imaginarios de Castoriadis (2013) y Durand (1971).

Los elementos que se muestran, pretenden contribuir a generar un reconocimiento de los referentes utilizados en las tradiciones y costumbres de pueblos originarios, que se están perdiendo debido al proceso de globalización de las culturas, así mismo, se espera que a partir de las metodologías planteadas y utilizadas se pueda generar un antecedente de la participación del diseño gráfico en la salvaguarda del PCI, a través de la captura de la imagen observada como representación social de los grupos y por tanto a partir de ésta contribuir en el reconocimiento de la memoria del pueblo, mediante el impacto y efecto que la imagen genera en las personas.

Palabras clave: diseño, inventarios de manifestaciones culturales, patrimonio inmaterial, salvaguardia.

Abstract : The main objective of the text presented is to expose the possibilities of the participation of graphic design as a social discipline in the generation of inventories of the intangible cultural heritage, through the image, in particular, of the cultural manifestation of "El Señor del Cerrito" in Jiquipilco, State of Mexico. A set of methodologies be show, for allow the analysis of the image from the theory of collective imaginary as a bet from the graphic design to safeguard the PCI based on the proposal made by UNESCO for this type of practices, as well as from the theory of imaginary of Castoriadis (2013) and Durand (1971).

The elements that are exposed, try to contribute to generate a recognition of the referents used in the traditions and customs of native peoples, which are being lost due to the process 
of globalization of cultures, likewise, it is expected that from the proposed methodology and used can generate a history of the participation of graphic design in the safeguarding of the PCI, through the capture of the image observed as social representation of the groups and therefore from this contribute to the recognition of the memory of the people, through the impact and effect that the image generates on people.

Keywords: design, inventories of cultural events, intangible heritage, safeguard.

\section{INTRODUCCIÓN}

Desde 1960 se plantea la idea de una sociedad global que se ha ido perfilando hacia la unificación de bienes y servicios, alrededor de todo el mundo, modificando y desapareciendo pequeños grupos que en un esfuerzo por conservar sus tradiciones y costumbres construyen su identidad a partir de los imaginarios colectivos, transmitiendo su ideología a partir de las manifestaciones culturales legadas de generación en generación.

Desde una mirada endógena, el planteamiento anterior se traduce en una preocupación ante la creciente expansión global, generando así una necesidad en los pueblos originarios, de reencontrar la memoria que les liga al pasado y les reivindica en el presente, mediante los elementos identitarios plasmados en su patrimonio inmaterial. Es la Organización de las Naciones Unidas para la Eduación, Ciencia y la Cultura (UNESCO, por sus siglas en inglés ), quien en 2013 , declara la necesidad de generar elementos que permitan acciones de resguardo del patrimonio cultural a favor de la conservación de las manifestaciones . Para desarrollar dichos elementos es necesario reconocer el significado de la cultura ysus expresiones ante los efectos de un mundo global.

Indica la Comisión Nacional de los Derechos Humanos (CNDH) en la “ Declaración de México sobre las políticas culturales” (CNDH, 1982: s.p.) que la cultura se define en su sentido más amplio como "(...) el conjunto de los rasgos distintivos, espirituales y materiales, intelectuales y afectivos que caracterizan a una sociedad o un grupo social".

A partir de la producción de cultura, el hombre manifiesta su forma de ver el mundo y de entenderlo, se relaciona y apropia de ciertos espacios para habitarlos. En la dinámica expuesta, genera expresiones o manifestaciones culturales que le permiten ser reconocido como individuo dentro de un gremio y como actor social frente a otros (identidad individual y colectiva). Se entiende por expresiones culturales o manifestaciones culturales a todo aquel "resultado de la creatividad de las personas, de grupos y sociedades que poseen un contenido cultural. Son actividades, bienes y servicios, cuya utilización o finalidades específicas encarnan o transmiten expresiones de cultura, independientemente del valor comercial que puedan tener" (UNESCO, 2013: s.p.).

La producción cultural en los grupos es expresada mediante el patrimonio cultural de los pueblos, mismo que es entendido por Medrano, como aquello que "alude al amalgama de elementos culturales que una sociedad llega a considerar suyos y a los que remite cuando ha de enfrentar el embate de los elementos ajenos a su cultura" (2016: 181-198). 


\section{Las tradiciones de los pueblos SE CONWIERTEN EN CRE ACLONES COLECTIVAS. RESGUARDALDAS DESDE LOS IMAGINARIOS CONSTRUIDOS para reflejar la identidad de los mismos.}

Aunado a lo anterior, la UNESCO expresa que:

El patrimonio cultural, tangible e intangible, es el testimonio de la creatividad humana y el substrato de la identidad de los pueblos. La vida cultural contiene simultáneamente la riqueza de poder apreciar y atesorar tradiciones de los pueblos, con la oportunidad de permitir la creación y la innovación de sus propias formas (2004: s.p.).

Las tradiciones de los pueblos se convierten en creaciones colectivas, resguardadas desde los imaginarios construidos para reflejar la identidad de los mismos. Menciona Castoriadis:

Ya que se ha establecido que la institución del mundo humano es también institución de un imaginario social que define el hacer, el decir, el pensar posible para una época determinada. Y si este imaginario social puede entenderse como flujo permanente de creación de significaciones imaginarias es necesario suponer también en los individuos, una imaginación radical como creación permanente de representaciones articuladas con los otros (2013: 207-214).

Por lo anterior, puede observarse a la cultura, como la creación constante de imaginarios colectivos reflejados en las manifestaciones culturales de los pueblos e identificadas en el patrimonio cultural de los lugares. Es así, que en la festividad del 3 de mayo en el Santuario del Señor del Cerrito, en Jiquipilco, Estado de México, se centra el ejemplo perfecto para identificar los imaginarios sociales que pueden y deben ser resguardados ante la inminente pérdida de costumbres y tradiciones de pueblos y culturas originarias.

El Santuario, que se enaltece en la cima del conocido "Monte Sagrado de los Mazahuas", según Romero (1991), es un espacio que permite el encuentro de dos etnias: mazahua y otomí, en un festejo lleno de significaciones y elementos de la imagen que han logrado construir parte de la identidad del pueblo de Jiquipilco. Visitantes de toda la República Mexicana y algunos extranjeros se dan cita para venerar al Señor de la Exaltación, mejor conocido como el Señor del Cerrito. Algunos peregrinos, otros danzantes, algunos más turistas y otros creyentes; recorren el camino que marca las 14 estaciones del viacrucis, en medio del bosque y entre cruces de madera en donde se dejan ramilletes de romero y piedras que guardan el cansancio de los que ascienden lenta, pero fervorosamente.

Ya en la cima, las vestimentas de las danzas de las pastoras, los moros, las listoneras, los aztecas y los arrieros, confeccionadas especialmente para el festejo, llenan de color la explanada y comienzan un desfile tranquilo entre la música de violines, guitarras y cantos en varios dialectos. Así mismo, se hacen presentes las imágenes de dualidad entre la lluvia y el fuego, elementos prehispánicos de fertilidad y fuerza que invocan al pasado y construyen en pequeños espacios la memoria de un pueblo. 
Cada año, la reunión de los danzantes y peregrinos evoca la historia y hace evidente la pérdida de elementos que construyen o construían el festejo en la memoria de quienes les observaron en alguna ocasión. El paso inminente del tiempo deja huella en la transformación o pérdida del patrimonio que no pudo ser legado.

Así lo declaran algunos de los actores que generan el patrimonio cultural desde la manifestación del Señor del Cerrito, como doña María, que hasta el 2017 había visitado el Santuario ocho veces consecutivas desde la comunidad de Amanalco, cuenta cómo se transforma el espacio y las diferentes acciones de los peregrinos y de los visitantes: "cada año ves algo diferentes, los colores, las telas, los bordados, hasta la gente es diferente", dice en una pequeña conversación frente a la iglesia doña María Sánchez, oriunda de Jiquipilco.

Ante la expresión de quienes comparten las festividades cada año, se distingue la solicitud expresada por la UNESCO para la generación de propuestas de salvaguardia de elementos de la cultura de los pueblos. Atendiendo a dicha necesidad, el diseño gráfico como disciplina, se une a la acción de resguardar la memoria y dar testimonio de las expresiones culturales en este caso en particular en Jiquipilco, Estado de México.

Inventariar, podría formar parte de una acción de resistencia ante la pérdida de rasgos culturales. La UNESCO propone salvaguardar el patrimonio inmaterial como principal factor de construcción de identidad y ante sus características efímeras, incluir al diseño gráfico en la confección de inventarios, podría reforzar el impacto en la reflexión social ante la pérdida de la cultura, que mediante la imagen hace evidente la ausencia y la nostalgia para recuperar lo que se ha perdido. Es necesario mencionar que el diseñador gráfico es un especialista en imagen, por lo que utiliza su expertis como una posibilidad en el ejercicio de la salvaguarda del PCI.

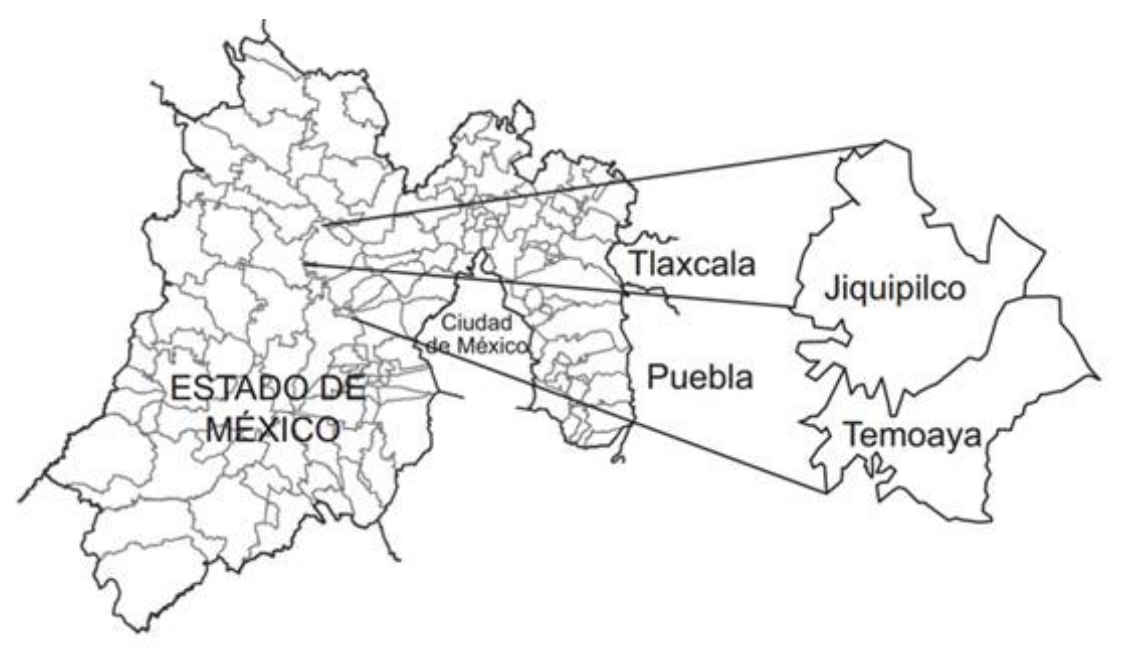

Figura 1. Ubicación de Jiquipilco, Estado de México. Fuente: (Marcos, B. Martínez, A. López, G. López, C Arteaga, T., 2016: 362). 


\section{METODOLOGÍA Y DISCUSIÓN}

Por la naturaleza del texto y dado que se presenta en la discusión una serie de metodologías que pueden ser consideradas en el ejercicio de salvaguarda desde el ámbito del diseño, es que se expone la discusión en conjunto con las metodologías y sus posibilidades en las propuestas de salvaguarda.

\section{Se observa un proceso metodológico cualitativo \\ Y UN ABORDAJE ETNOORÁFICO EN EL CONTEXTO PARA LA REALIZACIÓN DE LA INVESTIGACIÓN.}

Se observa un proceso metodológico cualitativo y un abordaje etnográfico en el contexto para la realización de la investigación.

Para la confección de inventarios del patrimonio inmaterial del Señor del Cerrito, se propone la utilización de tres metodologías; la primera, se basa en la construcción del inventario del patrimonio inmaterial que es formulada por la UNESCO ${ }^{[1]}$ y que se construye a partir de una serie de recomendaciones que se desglosan a continuación, indicando que son una propuesta inédita de esta institución, por lo que se rescata de manera textual:

\section{Identificación del elemento}

1. Nombre del elemento, tal como lo utiliza la comunidad o el grupo interesado.

2. Título breve y lo más informativo posible, con indicación del (de los) ámbito(s).

3. Comunidad(es) concernida(s).

4. Ubicación(es) física(s) del elemento.

5. Breve descripción: para comprender los alcances de la manifestación y su impacto dentro y/o fuera del colectivo.

\section{Características del elemento}

El segundo apartado está dedicado al desarrollo de los elementos que componen las manifestaciones culturales considerados patrimonio inmaterial y que se inscriben dentro de los siguientes parámetros.

1. Elementos materiales conexos.

2. Elementos inmateriales conexos.

3. Idioma(s), registro(s), nivel(es) de discurso.

4. Origen percibido. 


\section{Personas e instituciones relacionadas con el elemento}

En este espacio se deben describir a los actores que intervienen en la manifestación cultural a través de sus características individuales y los modos en cómo son difundidas.

1. Ejecutante(s)/intérprete(s): nombre(s), edad, sexo, condición social y/o categoría profesional, etc.

2. Otros participantes (por ejemplo, depositarios/custodios).

3. Usos consuetudinarios que rigen el acceso al elemento o a algunos aspectos del mismo.

4. Modos de transmisión.

5. Organizaciones concernidas (OSC [Organizaciones de la Sociedad Civil] y otras).

\section{Estado del elemento: viabilidad}

Para este punto y tras haber estudiado las características de las manifestaciones consideradas como patrimonio inmaterial, se analiza el estado de certeza o viabilidad que permite construir de forma exitosa el inventario para dotar de reconocimiento a los actores que lo gestan y a la comunidad que le resguarda geográfica o socialmente. Así mismo, se exponen las amenazas que pueden deteriorar o exterminar al patrimonio y a la transmisión de éste para finalmente proponer las medidas de salvaguardia adoptadas. Este último punto es tocado desde la disciplina del diseño gráfico a fin de proponer estrategias que serán abordadas en un apartado continuo de forma más detallada.

1. Amenazas que pesan sobre la práctica.

2. Amenazas que pesan sobre la transmisión

3. Disponibilidad de los elementos materiales y recursos conexos.

4. Viabilidad de los elementos materiales e inmateriales conexos.

5. Medidas de salvaguardia adoptadas.

\section{Acopio e inventario de los datos}

Para el penúltimo punto de la propuesta realizada por la UNESCO, se expone la intervención de la comunidad en donde se gestan las manifestaciones, su conocimiento y portaciones para la realización y la recolección de datos que se hace desde el diseño, auxiliado por herramientas como la fotografía etnográfica y la generación de estrategias de la imagen para una óptima comunicación.

1. Consentimiento de la comunidad o grupo al acopio e inventario de datos y participación en estas actividades.

2. Posibles restricciones del uso de los datos inventariados.

3. Experto(s): nombre y condición o pertenencia.

4. Fecha y lugar del acopio de datos. 
5. Fecha de incorporación de los datos a un inventario;

6. Artículo del inventario compilado por... [Nombre o nombres]

\section{Referencias bibliográficas, discográficas, audiovisuales y archivísticas}

Finalmente, en este apartado se concentran los datos de los espacios de consulta que sirven para la recolección, validación y difusión, y que integran el inventario del Patrimonio Cultural Inmaterial del caso específico para el presente proyecto.

La metodología que se expone desde la propuesta de la UNESCO es intervenida para el ejercicio particular que se propone en diferentes momentos por dos metodologías que se exponen a continuación.

La segunda metodología se basa en el análisis de los imaginarios colectivos que deriva de la interpretación de la obra de Durand (1971) y que se complementa con las aportaciones de Castoriadis (2013). Se realiza una reinterpretación de esta metodología, generando el siguiente esquema:

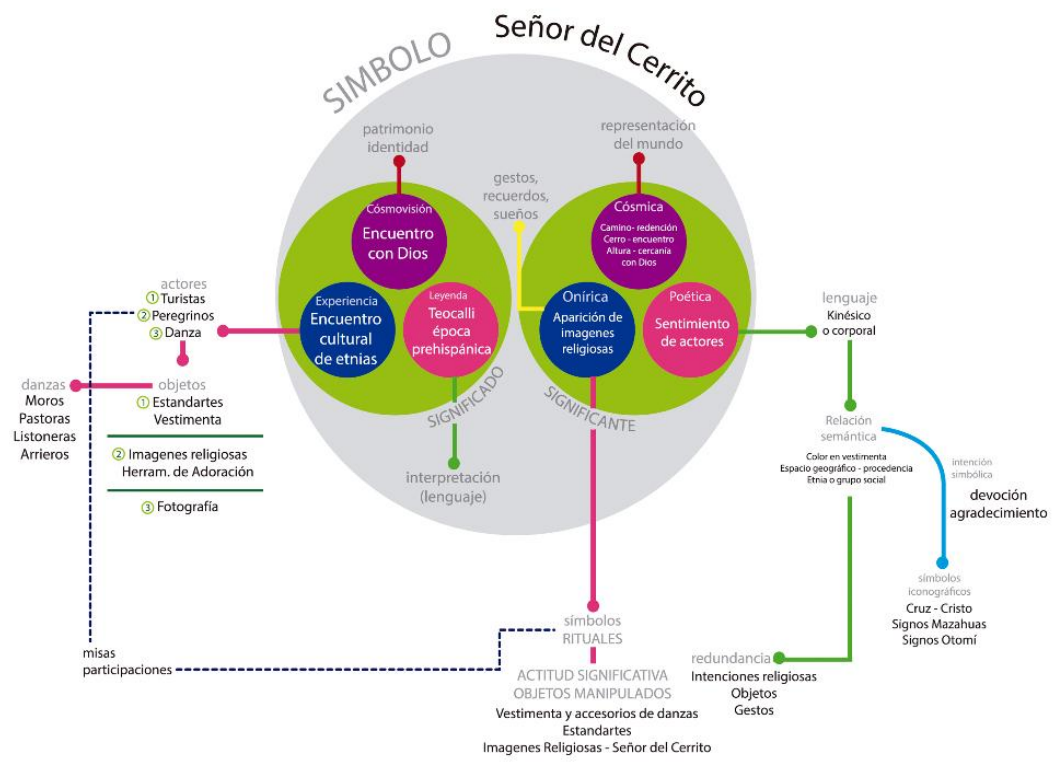

Figura 2. Modelo metodológico.

Fuente: Mora, (2018) a partir de Durand, (1971) y Castoriadis, (2013).

En la figura 2 se observa que el símbolo que determina la festividad del 3 de mayo en el Santuario del Señor del Cerrito en la comunidad de Santa Cruz Tepexpan en Jiquipilco, es el denominado Cristo del Señor del Cerrito, también conocido como "El Señor del Agua". El "Monte de los Mazahuas" es espacio que ya se usaba desde la época prehispánica para adorar a los dioses y lograr desde su cosmovisión una cercanía con ellos en la punta del cerro. 


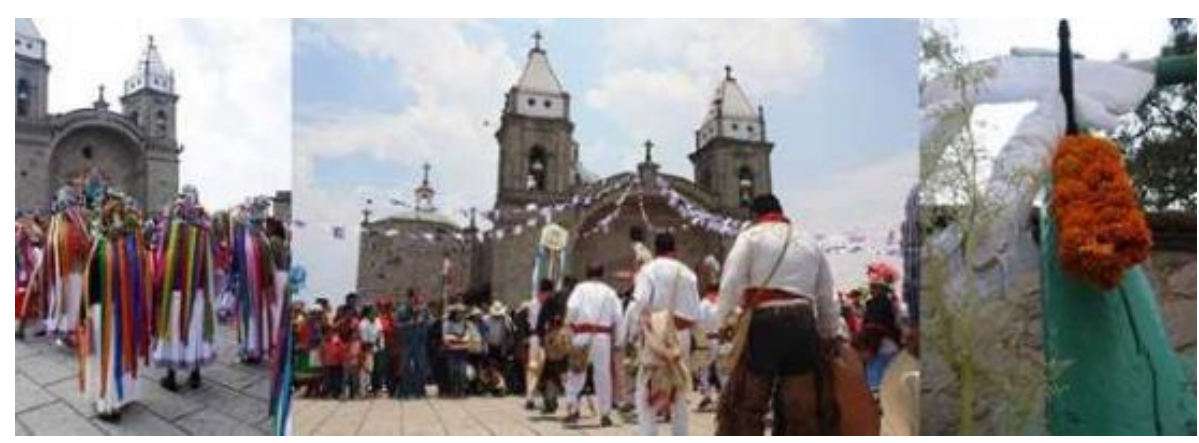

Figura 3. Festividad del Señor del Cerrito.

Fuente: Archivo personal: Mora, (2018).

\section{EL ELEMENTO OUE CONCENTRAA LOS TURISTAS Y VISITANTES ES LA VENERACIÓN AL SANTO PATRÓN.} que derivó en actividades económicas y sociales como el turismo.

La festividad del 3 de mayo es la más famosa en el lugar, aunque se documentan algunas de menos renombre a lo largo del año. El elemento que concentra a los turistas y visitantes es la veneración al santo patrón, que derivó en actividades económicas y sociales como el turismo.

Siendo una de las principales manifestaciones culturales en la zona, ha servido para la construcción de la identidad de los jiquipilquenses, que coadyuva para el reconocimiento del espacio geográfico y de la comunidad en general. Se concluye que se genera el sentido del significado del símbolo a través de los siguientes elementos:

Cosmovisión: como concepto está asociado con el encuentro de Dios con los hombres. Algunos autores como Ricardo Hernández (1986), cronista del lugar, narran que desde la época prehispánica, la altura de algunas elevaciones geográficas, como las montañas y los montes, son puntos de encuentro con los dioses, por lo que en los espacios geográficos se realizan rituales para mantener una relación cordial con ellos y en algunos casos se manifiestan mediante la construcción de templos para su adoración. El monte sagrado de los mazahuas, siguiendo al mismo autor, es un centro de adoración por parte de las etnias otomíes y mazahua. Forma parte de la construcción identitaria de los jiquipilquenses y construye el devenir histórico y social del territorio municipal, teniendo como elemento de patrimonio e identidad al espacio arquitectónico y las manifestaciones sociales que se desarrollan en él.

Experiencia: Dentro de la experiencia que implica visitar el Santuario del Señor del Cerrito en Santa Cruz Tepexpan, se permite la interacción con las etnias que producen el patrimonio inmaterial de la festividad del 3 de mayo en el lugar. La experiencia inicia con el recorrido que permite el ascenso hasta el Santuario en honor al Cristo del Agua o Señor del Cerrito, al llegar a la cima se pueden apreciar rituales católicos con 
orígenes prehispánicos que cuentan la historia de los pueblos vecinos, que se incluyen en los festejos.

Los actores que intervienen en la festividad son los turistas, los peregrinos y un elemento tradicional trascendental, son las danzas por las cuales se venera el 3 de mayo a la imagen del Señor del Cerrito en su Santuario. Los peregrinos y turistas provienen de diversas partes del Estado de México y de la República Mexicana, mientras que las danzas, aún con diferente procedencia, pueden clasificarse según su representación en palabras de los danzantes y personas originarias de la zona en: Danza de los Moros, Danza de las Pastoras (Azules, Blancas y Rosas), Danza de las Listoneras y Danza de los Arrieros.

Cada grupo asume un papel importante en los festejos y recurren a accesorios como las vestimentas y estandartes para reconocerse entre otros grupos, así mismo, los peregrinos se acompañan de imágenes del Señor del Cerrito o de los Santos Patrones del lugar de donde provienen, de algunas herramientas de adoración como el sahumador o instrumentos musicales de acompañamiento. Finalmente, los turistas se valen de la experiencia fotográfica para documentar su visita.

Leyenda: Está construida a partir de los registros en el código Borges y otras narraciones orales de personas adultas que las han escuchado de generaciones pasadas. Por otro lado, el significante está conformado por los elementos siguientes:

Cósmico: Tiene relación con el encuentro con Dios que se suscita en el plano de la cosmovisión, el monte representa el lugar más cercano a una divinidad Sagrada: a los dioses prehispánicos de la religión politeísta de los nahuas o al Dios de "divinidad trinidad" que representa a la iglesia católica; el Santuario simboliza a la casa de Dios y el albergue de quienes lo buscan y el camino de ascenso a éste simboliza el sacrificio y la redención del peregrino que busca consuelo en la divinidad todo poderosa.

Onírico: Se asocia al elemento onírico con la aparición de las imágenes religiosas y los milagros que éstas realizan a las personas que posteriormente se convierten en devotos del Señor del Cerrito, agradeciendo por las peticiones cumplidas o solicitando nuevas plegarias.

Poético: Representado con el sentir de los visitantes: peregrinos o turistas que pueden apreciar y ser parte de la actividad religiosa y cultural, se manifiesta mediante un lenguaje kinésico o corporal que permite hacer visible el patrimonio intangible expresado mediante los actores de la festividad.

Lo anterior, genera una relación semántica mediante los colores usados en la vestimenta de las danzas, la etnia o grupo social al que pertenecen y el espacio de procedencia de los visitantes.

\section{La intención simbólica se entiende como}

\section{LA HIPONIMIA DE LOS ELEMENTOS.}

ES DECIR, OUE SE ASOCLA A IN CONJINTO DE MANIFESTACIONESOUE SE RECONOCEN gracias a la figura del Señor del Cerrito. 
La intención simbólica se entiende como la hiponimia ${ }^{[2]}$ de los elementos, es decir, que se asocia a un conjunto de manifestaciones que se reconocen gracias a la figura del Señor del Cerrito. Ésta se da mediante la veneración y agradecimiento a la imagen religiosa que representa a Dios y de ella se derivan la imagen de las danzas, la música, las representaciones y las peregrinaciones; sin embargo, también existe una intención de difundirla turísticamente, esto por parte de las instancias gubernamentales que en los últimos años han decidido proyectarla de forma municipal y estatal.

Los símbolos icnográficos, que se encuentran en este análisis, son el Cristo que representa al Señor del Cerrito, los elementos de la etnia otomí (vestimenta y accesorios) y los elementos de la etnia mazahua (vestimenta y accesorios ); tienen redundancia en otras proyecciones religiosas, debido a que las danzas y los peregrinos que visitan al Señor del Cerrito el 3 de mayo , también lo hacen en otras fechas a lo largo del año (como en la fiesta de Santa Teresa el 15 de octubre, celebrada en el mismo Santuario ) y en otros espacios de veneración católica de todo el país en donde son invitados para los festejos de diversas imágenes religiosas.

Finalmente, se puede apreciar que la actitud significativa que detona la manipulación de objetos, se aprecia principalmente en el uso de estandartes por parte de las danzas, en las imágenes del Señor del Cerrito que acompañan a los peregrinos y en la vestimenta de las danzas.

Por último, la tercera propuesta metodológica, con la que se propone contener la información antes mencionada en un elemento editorial propuesto desde el diseño gráfico y que permita la reflexión y la difusión de los elementos del patrimonio inmaterial ligados a la representación del imaginario colectivo se explica a continuación:

Estructura:

1. Conocimiento del caso de estudio: en este espacio se aborda la metodología de análisis de la imagen para conocer el estado del caso de estudio y determinar su viabilidad.

2. Descripción de imagen: se realiza un registro fotográfico y documental que permita contener el patrimonio inmaterial. El conocimiento de la técnica fotográfica y sobre la imagen como objeto de estudio de la disciplina del diseño, permiten un ejercicio descriptivo profesional.

3. Evaluación del proyecto editorial: se hace un vaciado de la información en un contendedor editorial que permita las reglas propias de la legibilidad e impacto de la imagen, capaz de generar una correcta lectura de la información.

4. Determinar estrategias de difusión y salvaguardia: complementar la generación editorial, con información sobre dónde y cómo se regresará la información a los actores y a la sociedad en general, como parte de la difusión. 
Esta última metodología se fundamenta en el índice cinco de la propuesta original de la UNESCO que servirá para el acopio de datos pertenecientes al patrimonio inmaterial de Jiquipilco.

De esta manera se encuentran tres momentos en la construcción del inventario : la producción que refiere a la propuesta de la UNESCO, el análisis del imaginario a partir de Castoriadis (2013) y la de proyección que sugiere la producción y que se refiere a la metodología usada para el diseño del inventario como objeto editorial, una propuesta desde la disciplina del diseño que se fundamenta en el conocimiento previo del elemento o elementos de salvaguarda reconocidos a partir de las dos primeras metodologías.

\section{RESULTADOS}

Las metodologías expresadas en este texto forman parte de un ejercicio mayor para la confección de inventarios del patrimonio inmaterial del festejo del 3 de mayo en honor al Señor del Cerrito en la comunidad de Santa Cruz Tepexpan en Jiquipilco, gestada a partir de la necesidad de recuperar y resguardar la memoria del pueblo, posibilitando la reflexión sobre la construcción colectiva de la identidad a partir de los imaginarios que se construyeron en el pasado y perdieron significado con el paso del tiempo. Las imágenes sin duda a partir de la representación fotográfica dan cuenta de la tradición y observada desde la mirada del diseño gráfico como especialista en imagen podrá ofrecer una serie de interpretaciones y significaciones individuales y colectivas sobre la tradición como parte de la historia de los grupos. Es un ejemplo el caso que se presenta.

Los resultados que se muestran forman parte de un ejercicio de reflexión profunda que se extiende también a otras manifestaciones culturales del municipio, sin embargo, la festividad abordada en este artículo, desde la postura de quienes presentamos el texto, tiene un impacto y reconocimiento mayor a causa de la afluencia turística que presenta el santuario y con ello, la exposición que tiene al contacto con actores de culturas diversas que intercambian elementos propios con quienes generan el patrimonio. Durante el tiempo que se ha dedicado a la documentación fotográfica para la construcción del inventario, se ha hecho evidente la transformación del patrimonio inmaterial como es el caso de las vestimentas de los grupos que acompañan al Señor del Cerrito; se han dejado a un lado las sandalias de piel para usar calzado de moda o se han combinado elementos de culturas extranjera para expresar la propia danza. Se observa que esta posibilidad mantendrá un incremento derivado de los sincretismos en especial en el contexto planteado; por lo anterior se sugiere importante la labor de inventariar el PCI desde cualquier iniciativa formal.

Documentar e inventariar a partir de los elementos presentados, pareciera que es el primer caso que se ha desarrollado desde la disciplina del diseño, se espera generar interés en la dinámica como posibilidad de participación del ejercicio profesional de la disciplina sobre todo para el análisis y la construcción de objetos editoriales. Existen pendientes 
desde la labor investigativa del caso que se presenta y otros por lo que las estrategias que acompañan al mismo como ejercicio de salvaguardia del patrimonio se siguen desarrollando y por tanto cumpliendo con la condición de las metodologías antes mencionadas para generar vínculos entre los actores que gestan el patrimonio, la sociedad civil, la academia y las instancias gubernamentales.

\section{CONCLUSIONES Y RECOMENDACIONES}

Como se ha mencionado, la investigación generada en el Santuario del Señor del Cerrito en Jiquipilco, Estado de México, forma parte del desarrollo de un inventario que se propone desde el área del diseño gráfico y se vincula de forma multidisciplinaria con áreas como la psicología social, la antropología y auxilia en la construcción de elementos editoriales que resguardan el patrimonio inmaterial de los pueblos con la finalidad de coadyuvar en mantener la memoria de los mismos, mediante la representación social lograda por la imagen que representa e intenta resguardar la riqueza cultural del lugar frente al presente de un mundo global.

Los elementos generados hasta el momento, pretenden contribuir en el reconocimiento de la memoria del pueblo, mediante los efectos que la imagen crea en las personas conformando representación social. Los públicos a los que se dirigen tienen características diferentes, pero pueden clasificarse en dos gremios: el de los actores y productores del patrimonio que en su mayoría son personas adultas que han resguardado las acciones y creencias del pueblo y los jóvenes de la comunidad de Jiquipilco, donde se ha roto el vínculo cultural por falta de la identificación de los imaginarios colectivos y sus significaciones. En ambos casos, se busca generar una reflexión y una invitación a sumarse al rescate de los elementos inmateriales para poder legarlos a generaciones venideras, como parte de la identidad del pueblo.

De esta manera, se evidencia la capacidad del diseño para abordar fenómenos culturales y sociales complejos. Se reconoce el abordaje del diseño en factores en donde se puede expresar el sentir de los grupos, comunidades o sociedades.

El ejercicio de investigación que se presenta, reconoce la mirada de hombres y mujeres que en las localidades día con día reconstruyen su identidad entre el pasado y el presente. El ejercicio desde la disciplina del diseño que se exhibe, podrá funcionar como apuesta metodológica a la salvaguarda del legado de los pueblos originarios a partir de una labor que tiene sus bases en el conocimiento de la imagen como representación social.

\section{FUENTES DE CONSULTA}

Castoriadis, C. (2013), La institución imaginaria de la sociedad, Fábula Tusquets editores, México. 
Comisión Nacional de los Derechos Humanos (CNDH) (2018), Derechos culturales y Derechos Humanos, UNESCO y SEGOB, México.

Durand, G. (1971), La imaginación simbólica, Amorrotu, Argentina.

Hernández, R. (1986), Monografía Municipal: Jiquipilco, Estado de México, GEM: Secretaría de Educación, Cultura y Bienestar Social, México.

Marcos, B. Martínez, A. López, G. López, C. Arteaga, T. (2016), "La biomasa de los sistemas productivos de maíz como alternativa a la captura de carbono". Revista Internacional de Contaminación Ambiental, vol. 32, núm. 3, pp. 361-367.

Medrano, G. (2016), “Allá en la Plaza me encontré con un viejito conversón. Identidad y cultura en las tradiciones Guanajuatenses”. En Identidades y Patrimonios. Encrucijada entre lo material y lo intangible, Fontmara, México, pp. 181-198.

Organización de las Naciones Unidas para la Educación, la Ciencia y la Cultura (UNESCO) (2003), Convención para la salvaguardia del Patrimonio Cultural Inmaterial, UNESCO, París.

Organización de las Naciones Unidas para la Educación, la Ciencia y la Cultura (UNESCO) (2004), Agenda 21, UNESCO, París.

Organización de las Naciones Unidas para la Educación, la Ciencia y la Cultura (UNESCO) (2011), Patrimonio Cultural Inmaterial. Kit sobre el patrimonio cultural inmaterial, UNESCO, París.

Organización de las Naciones Unidas para la Educación, la Ciencia y la Cultura (UNESCO ) (2013), Identificar e inventariar el patrimonio cultural inmaterial, UNESCO, París.

Romero, J. (1991), XIQUIPILCO Jiquipilco, Instituto Mexiquense de Cultura, México.

\section{Notas}

[1] En 2003, la UNESCO emite un llamado a la salvaguardia del patrimonio para confeccionar instrumentos que permitan salvaguardar los elementos del patrimonio, especialmente, los inmateriales como la vestimenta, la música y toda aquella acción efímera que represente a los colectivos desde la actuación y la presencia ligada a otros elementos, incluso materiales. Disponible en http://unesdoc.unesco.org/ images/0013/001325/132540s.pdf.

[2] Según el Diccionario de la Real Academia Española, hiponimia es entendida como la relación de significado de un hipónimo con respecto a su hiperónimo. 